Research article Open Access

\title{
Expression of FOXA1 and GATA-3 in breast cancer: the prognostic significance in hormone receptor-negative tumours
}

\author{
André Albergaria ${ }^{1,2}$, Joana Paredes², Bárbara Sousa², Fernanda Milanezi², Vítor Carneiro ${ }^{3}$, \\ Joana Bastos ${ }^{4,5}$, Sandra Costa1, Daniella Vieira ${ }^{6}$, Nair Lopes ${ }^{2}$, Eric W Lam7, Nuno Lunet ${ }^{4,5}$ and \\ Fernando Schmitt 2,8
}

\author{
1Development Domain, Institute of Life and Health Sciences (ICVS), School of Health Sciences of Minho University - Campus de Gualtar, Braga \\ 4710-057, Portugal \\ ${ }^{2}$ Cancer Genetics Group, Institute of Molecular Pathology and Immunology of Porto University (IPATIMUP), Rua Dr Roberto Frias s/n, Porto 4200- \\ 465, Portugal \\ ${ }^{3}$ Department of Pathology of Hospital of Divino Espirito Santo, Rua da Grotinha, Ponta Delgada 9500-370, Portugal \\ ${ }^{4}$ Department of Hygiene and Epidemiology, University of Porto Medical School, Alameda Prof. Hernâni Monteiro, Porto 4200-319, Portugal \\ 5 Institute of Public Health of the University of Porto (ISPUP), Praça Gomes Teixeira s/n, Porto 4099-002, Portugal \\ ${ }^{6}$ Department of Pathology, Federal University of Santa Catarina, Campus Reitor João David Ferreira Lima, Florianópolis, Santa Catarina CEP 88040- \\ 970, Brazil \\ 7Department of Oncology, Cancer Research UK Laboratories, MRC Cyclotron Building, Imperial College of London, Hammersmith Hospital, Du Cane \\ Road, London W12 OHS, UK \\ ${ }^{8}$ Department of Pathology, Medical Faculty of University of Porto, Alameda Prof. Hernâni Monteiro, Porto 4200-319, Portugal
}

Corresponding author: Fernando Schmitt, fschmitt@ipatimup.pt

Received: 5 Jan 2009 Revisions requested: 9 Feb 2009 Revisions received: 26 May 2009 Accepted: 23 Jun 2009 Published: 23 Jun 2009

Breast Cancer Research 2009, 11:R40 (doi:10.1186/bcr2327)

This article is online at: http://breast-cancer-research.com/content/11/3/R40

(C) 2009 Albergaria et al.; licensee BioMed Central Ltd.

This is an open access article distributed under the terms of the Creative Commons Attribution License (http://creativecommons.org/licenses/by/2.0), which permits unrestricted use, distribution, and reproduction in any medium, provided the original work is properly cited.

\begin{abstract}
Introduction The expression of additional genes, other than oestrogen receptor (ER), may be important to the hormoneresponsive phenotype of breast cancer. Microarray analyses have revealed that forkhead box A1 (FOXA1) and GATA binding protein 3 (GATA-3) are expressed in close association with $E R \alpha$, both encoding for transcription factors with a potential involvement in the ER $\alpha$-mediated action in breast cancer. The purpose of this study was to explore if the expression of FOXA1 and GATA-3 may provide an opportunity to stratify subsets of patients that could have better outcome, among the ER $\alpha$ negative/poor prognosis breast cancer group.
\end{abstract}

Methods We evaluate FOXA1 and GATA-3 expression in 249 breast carcinomas by immunohistochemistry, associating it with breast cancer molecular markers, clinicopathological features and patient's survival. The clinicopathological features and immunohistochemical markers of the tumours were compared using the chi-square test and ANOVA. Disease-free survival was analysed through Kaplan-Meier survival curves and Cox regression.
Results FOXA1 expression was demonstrated in $42 \%$ of invasive carcinomas, while GATA-3 was detected in $48 \%$ of the cases. FOXA1 expression was inversely associated with tumour size, Nottingham Prognostic Index, histological grade, lymph vascular invasion, lymph node stage and human epidermal growth factor receptor-2 (HER-2) overexpression, while GATA3 expression showed inverse association with histological grade and HER-2. Both FOXA1 and GATA-3 were directly associated with $\mathrm{ER} \alpha$ and progesterone receptor. Among FOXA1-positive tumours, $83.1 \%$ are comprised in the luminal A subtype, similar to GATA-3 where $87.7 \%$ of positive tumours were classified within this molecular subtype. In the subset of $E R \alpha$-negative patients, those who were FOXA1-negative had a 3.61-fold increased risk of breast cancer recurrence when compared with the FOXA1-positive.

Conclusions FOXA1 was a significant predictor of good outcome in breast cancer, whereas GATA-3 was an important luminal marker. The expression of FOXA1 may be used for risk stratification among $E R \alpha$-negative patients.

CK: cytokeratin; EGFR: epidermal growth factor receptor; ER: oestrogen receptor; FOXA-1: forkhead box A1; GATA-3: GATA binding protein 3; HER-2: human epidermal growth factor receptor 2; PBS: phosphate-buffered saline; P-cadherin: placental cadherin; PR: progesterone receptor. 


\section{Introduction}

The expression of oestrogen receptor (ER) is an important prognostic and predictive factor in breast cancer and has relevant implications for the biology of this type of carcinomas. Patients with tumours that express ER have a longer diseasefree interval and overall survival than patients with tumours lacking ER expression [1].

According to international treatment guidelines for early breast cancer, patients with $\mathrm{ER} \alpha$ and/or progesterone receptor (PR) expression should receive an adjuvant endocrine therapy, since their expression is associated with higher response rates to anti-hormonal treatment [2]. However, the association between $\mathrm{ER} \alpha$ expression and hormonal responsiveness is far from perfect, since approximately $30 \%$ of ER-positive tumours do not respond to hormonal treatment and 5 to $15 \%$ of ERnegative tumours curiously respond to endocrine therapy [3].

In order to overcome and explore this unpredictable breast tumour behaviour, numerous studies, based on cDNA microarrays, have shown that the gene expression profile in breast cancer can provide molecular phenotypes that identify distinct tumour subclasses [4-6], patient survival prediction [5-7], and differences in tumour biology or clinical features. The molecular classification of breast cancers distinguishes three major subtypes: the ER-positive/luminal-like subtype, a gene expression cluster characteristic of the luminal cells and anchored by a cluster of transcription factors that include ER; the basal-like subtype, comprising tumours that express basal cell markers (namely keratin 5 , keratin 14 , integrin $\beta_{4}$ and laminin); and the human epidermal growth factor receptor-2 (HER-2)-overexpressing subtype, usually associated with gene amplification of the HER-2 proto-oncogene and high expression of several genes in the ERBB2 amplicon at 17q22.24 [4,5,8]. These studies have largely contributed to understanding the complex behaviour of certain types of breast cancer, including the ones that respond better to endocrine therapies, regardless of ER expression.

Oestrogen plays an important role in the regulation of growth, proliferation and differentiation of mammary epithelium. The action of oestrogen is mediated through the ER, which functions as an oestrogen-activated transcription factor. The expression of an additional set of genes that is not part of the canonical oestradiol-response pathway may also be essential in clarifying the hormone-responsive phenotype, since intrinsic differences in the list of transcription factors bound to the $E R$ gene promoter have been described [9].

Additionally, the distinct behaviour observed between ER-positive luminal subtypes $A$ and $B$ (a subgroup of tumours with low to moderate expression of the luminal-specific genes including the ER cluster) may in part be due to the influence of additional factors, including transcriptional factors, co-activators and co- repressors modulating ER activity [10], which can also be explored towards a therapeutic purpose.

In 2004 Lacroix and Leclercq compiled considerable extensive data describing the strong association and cross-talk between ER $\alpha$, forkhead box A1 (FOXA1) and GATA binding protein 3 (GATA-3) [11]. In most of these studies, GATA-3 and FOXA1 have been highlighted within the ER $\alpha$ pathway in the luminal A subtype [4-6,12]; FOXA1, a forkhead family transcription factor, has been receiving considerable attention, since it interacts with cis-regulatory regions of heterochromatin, enhancing the interaction of ER $\alpha$ with DNA [13]. Carroll and colleagues recently described several robust data demonstrating the requirement of FOXA1 for optimal expression of nearly $50 \%$ of ER $\alpha$-regulated genes and oestrogen-induced proliferation $[13,14]$.

FOXA1 is expressed in the liver, pancreas, bladder, prostate, colon and lung, as well as in the mammary gland, and can bind to the promoters of more than 100 genes associated with metabolic processes, regulation of signalling pathways and cell cycle [15-17]. Some studies have shown that FOXA1 can act either as a growth stimulator/activator or as a repressor. As a stimulator, FOXA1 binds to chromatinised DNA and opens the chromatin, enhancing binding of ER $\alpha$ to its target genes [18] - which suggests a growth-promoting role for this forkhead protein [14,18]. In breast cancer, however, FOXA1 overexpression can also block the metastatic progression by influencing the expression of the BRCA1-associated cell-cycle inhibitor p27 and promoting E-cadherin expression $[19,20]$. Recent studies also suggest FOXA1 as a favourable prognostic factor in breast cancer, with potential relevance in the subclassification of luminal/ER-positive tumours into two subgroups with different biological behaviour and prognosis, the luminal $A$ and the luminal $B$ [5].

FOXA1 and ER $\alpha$ have been explored as potential participants involved in mammary tumours together with another gene, GATA-3 [21,22], which regulates the lineage determination and differentiation of many cells types. In the breast, GATA-3 plays a central role in luminal epithelia differentiation and the subsequent formation of the ductal tree of differentiated epithelial cells [23], suggesting that this protein might be involved in breast tumorigenesis [24].

Meta-analysis of four microarray datasets indicated that GATA-3 was a strong predictor of clinical outcome in breast tumours and is among the best predictors of ER-positive status [4,9,25-27]. Among all of the molecular subgroups of breast cancer, the luminal $A$ subtype has a relatively favourable outcome and the highest GATA-3 and ER $\alpha$ expression levels, compared with luminal $B$ and basal-like breast carcinomas [24]. 
As a result of all of these extensive studies underlying GATA3 and ER $\alpha$ in mammary epithelia, it has been clear that GATA3 is a crucial regulator of tumour differentiation and suppressor of tumour dissemination [22]. It has been also suggested that these functions in mammary luminal cells may be linked by transcriptional regulators, whereas FOXA1 appears as a candidate gene, which is necessary for the transcriptional activity of ER $\alpha$ and its binding to oestrogen-responsive elements in target gene promoters $[13,18]$. As FOXA1 may also be a downstream effector of GATA-3, it may be a bridge between GATA-3 and ER pathways [22], controlling and regulating the biology of luminal mammary cells, breast cancer progression and behaviour.

Based on this intricate and functional complex between FOXA1 and GATA-3 in breast cancer biology, it is reasonable to consider that these transcription factors, in addition to $E R \alpha$, are important in establishing and clarifying the hormoneresponsive phenotype and prognosis in breast cancer. This gene set may therefore be used as a diagnostic tool for more accurate determination of ER $\alpha$ status, in the decision on endocrine therapeutic strategies, as well as in the assessment of breast cancer patient's outcome.

In the present study we provide an immunohistochemical approach studying FOXA1 and GATA-3 expression, in order to predict the tumour behaviour of breast cancer patients. In the whole series, we verified that patients harbouring FOXA1positive tumours show a better disease-free survival. Interestingly, and for the first time, we also found the same power of risk stratification among the ER $\alpha$-negative breast cancer patients, demonstrating the clinical importance of this biomarker in breast cancer molecular classification and prognosis. These results show that FOXA1 and ER $\alpha$ should be used together in order to subclassify breast carcinomas and to predict the outcome of breast cancer patients.

\section{Materials and methods Patient selection}

A series of 249 cases of primary operable invasive breast carcinomas were retrieved from the files of the Department of Pathology, Hospital do Divino Espírito Santo, Azores, Portugal and from the Federal University of Santa Catarina, Florianopolis - SC, Brazil. These samples were obtained from patients with age ranging from 30 to 89 years. All of the formalin-fixed paraffin-embedded histological sections were reviewed by three pathologists (VC, FS and FM) and the diagnoses were confirmed as follows: 208 invasive ductal carcinomas, seven invasive lobular carcinomas, three mixed breast carcinomas, three tubular breast carcinomas, eight medullary breast carcinomas and 20 invasive breast carcinomas of other special histological types. These tumours have been fully characterized for clinical and pathological features - namely, age, tumour size, histological type, lymph nodes invasion, tumour grade, Nottingham Prognostic Index, ER $\alpha$, PR and HER-2 status. The patients' clinical and pathological characteristics are summarized in Table 1.

Follow-up information was available for 218 cases, ranging from a minimum of 2 months to a maximum of 129 months (median 32 months). The disease-free survival data interval was evaluated and defined as the time from the date of surgery to the date of breast-cancer-derived relapse/metastasis. Owing to the short follow-up of the studied series and the consequent limited number of death events, overall survival was not analysed.

The present study was conducted under the national regulative law for the usage of biological specimens from tumour banks, where the samples are exclusively available for research purposes in the case of retrospective studies.

\section{Tissue microarray construction and immunohistochemical analysis}

Representative areas of different lesions were carefully selected on haematoxylin and eosin-stained sections and were marked on individual paraffin blocks. Two tissue cores $(2 \mathrm{~mm}$ in diameter) were obtained from each selected specimen and were precisely deposited into a recipient paraffin block using a tissue microarray workstation (tissue microarray builder ab1802; Abcam, Cambridge, UK) as described elsewhere $[28,29]$. In each tissue microarray block, non-neoplastic breast tissue cores were also included as controls.

Immunohistochemistry was performed in $3 \mu \mathrm{m}$ formalin-fixed, paraffin-embedded sections. Expression for the most commonly used breast cancer markers - namely, HER-2, ER, PR, $\mathrm{P}$-cadherin, epidermal growth factor receptor (EGFR), vimentin and basal cytokeratins (CK5, CK14) - was assessed. The immunohistochemistry technique was performed using an Envision Detection System (DAKO Cytomation Envision System HRP; DAKO Corporation, Carpinteria, CA, USA) or the classical streptavidin - avidin - biotin complex method according to the manufacturer's instructions. Imunohistochemistry assay conditions and antibodies specifications were based on previously published studies from our group [28-30]. Immunoreactivity for ER $\alpha$, PR, P-cadherin, CK5, CK14, EGFR, vimentin and HER-2 was classified by estimating the percentage of tumour cells showing characteristic staining, in accordance with previous work [28-30].

Expression of FOXA1 was analysed using a mouse monoclonal antibody (clone 2F83, ab40868; AbCam), as well as GATA-3 expression (clone H-63-31, Sc-268; Santa Cruz Biotechnology Inc., Santa Cruz, CA, USA). Sections were deparaffinized with xylene and rehydrated in a series of decreasing concentration of ethanol solutions. Heat-induced epitope retrieval was carried out in $10 \mathrm{mM}$ citrate buffer (sodium citrate) $(\mathrm{pH} 6)$ or in $1 \mathrm{mM}$ ethylenediamine tetraacetic acid buffer (pH 8) (LabVision Corporation, Fremont, CA, USA), in a $98^{\circ} \mathrm{C}$ 
Breast Cancer Research Vol 11 No 3 Albergaria et al.

Table 1

Patient characteristics and tumour parameters

\begin{tabular}{|c|c|}
\hline Variable & Data \\
\hline \multicolumn{2}{|l|}{ Age at diagnosis (years) } \\
\hline Mean and standard deviation & $57 \pm 14.2$ \\
\hline Range & 59 (minimum 30; maximum 89) \\
\hline \multicolumn{2}{|l|}{ Tumour size (mm) } \\
\hline Mean and standard deviation & $32 \pm 21 \mathrm{~mm}$ \\
\hline Range & 145 (minimum 5; maximum 150) \\
\hline \multicolumn{2}{|l|}{ Lymphovascular invasion } \\
\hline Present & $111(44.6)$ \\
\hline Absent & $111(44.6)$ \\
\hline Not assessed & $27(10.8)$ \\
\hline \multicolumn{2}{|l|}{ Lymph node sage } \\
\hline Negative & $111(44.6)$ \\
\hline 1 to 3 lymph nodes & $57(22.9)$ \\
\hline$>3$ lymph nodes & $54(21.7)$ \\
\hline Not assessed & $27(10.8)$ \\
\hline \multicolumn{2}{|l|}{ Tumour grade } \\
\hline Grade I & $51(20.5)$ \\
\hline Grade II & $116(46.6)$ \\
\hline Grade III & $82(32.9)$ \\
\hline \multicolumn{2}{|l|}{ Histology } \\
\hline Invasive ductal carcinoma (not otherwise specified) & $208(83.5)$ \\
\hline Invasive lobular carcinoma & $7(2.8)$ \\
\hline Mixed & $3(1.2)$ \\
\hline Tubular & $3(1.2)$ \\
\hline Medullary & $8(3.3)$ \\
\hline Other special types & $20(8.0)$ \\
\hline \multicolumn{2}{|l|}{ Nottingham Prognostic Index } \\
\hline$<3.4$ & $46(18.5)$ \\
\hline 3.4 to 5.4 & $106(42.6)$ \\
\hline$>5.4$ & $55(22.0)$ \\
\hline Not assessed & $42(16.9)$ \\
\hline \multicolumn{2}{|l|}{ Oestrogen receptor- $\alpha$ status } \\
\hline Positive & $141(56.6)$ \\
\hline Negative & $107(43.0)$ \\
\hline Unknown & $1(0.4)$ \\
\hline \multicolumn{2}{|l|}{ Progesterone receptor status } \\
\hline Positive & $89(35.8)$ \\
\hline Negative & $154(61.8)$ \\
\hline Unknown & $6(2.4)$ \\
\hline \multicolumn{2}{|l|}{ Human epidermal growth factor receptor 2 status } \\
\hline Positive & $42(16.9)$ \\
\hline Negative & $201(80.7)$ \\
\hline Unknown & $6(2.4)$ \\
\hline
\end{tabular}

Data presented as $n(\%)$ unless stated otherwise. 
water bath, for 14 and 20 minutes for FOXA1 and GATA-3, respectively. After cooling retrieval solutions for at least 30 minutes at room temperature, the slides were treated for 10 minutes with $3 \% \mathrm{H}_{2} \mathrm{O}_{2}$ in methanol, in order to block endogenous peroxidase. Slides were incubated with monoclonal antibodies for FOXA1 (1:450) and GATA-3 (1:100) for 2 hours at room temperature and were labelled with the Envision Detection System from DAKO. Colour reaction product was developed with 3,3'-diaminobenzidine, tetrahydrochloride (DAB plus; DAKO Glostrup, Denmark) as a substrate, and nuclear contrast was achieved with haematoxylin/ammoniacal water counterstaining. Formalin-fixed, paraffin-embedded sections from normal breast gland were used as FOXA1 and GATA-3 positive controls. Negative controls were performed by replacing the primary antibody with PBS/nonimmune mouse serum.

The scoring method used for FOXA1 and GATA-3 expression was based on a semi-quantitative scoring system previously described by Thorat and colleagues, where the cutoff value for FOXA1 positivity was validated [31]. In this scoring system, the percentage of staining was categorized as: $0=$ no nuclear expression; $1=1$ to $10 \%$ positive tumour nuclei; $2=11$ to $20 \%$; and so on until a maximum score of $10=91$ to $100 \%$ positive tumour nuclei. The intensity was scored as: $1+=$ weak staining; $2+=$ moderate staining; and $3+=$ strong staining. The numeric final score was generated by the multiplication product of percentage and intensity of nuclear expression (scoring $=$ percentage $\times$ intensity) $[10,32]$. Based on this semiquantitative scoring system, scores between 0 and 3 were classified as negative, and scores $\geq 4$ to a maximum of 30 were considered positive.

\section{Statistical analysis}

Statistical analysis was performed using Stata $^{\mathrm{TM}}$, version 9.2 software (StataCorp, College Station, TX, USA). Continuous variables were presented as the mean \pm standard deviation, and categorical variables were presented as the number (percentage). The clinicopathological features and immunohistochemical markers of the tumours were compared across groups of expression of FOXA1 and GATA-3 using analysis of variance and the chi-square test, respectively, for continuous and categorical variables.

Survival curves were estimated by the Kaplan - Meier method using the log-rank test to assess significant differences for disease-free patient survival. A maximum cutoff value of 60 months (5 years) was considered, since this is the expected clinical time for breast cancer recurrence. Cox regression models were fitted to estimate hazard ratios and the corresponding 95\% confidence interval for the classical prognostic factors, FOXA1 and GATA-3. In all analyses, a significant level of $5 \%$ was considered.

\section{Results \\ FOXA1 and GATA-3 expression in normal and malignant breast tissues}

From the total 249 cases, only cases with clear and restricted nuclear expression for FOXA1 and GATA-3 were selected for immunohistochemistry classification. Three representative cases were selected to build a panel, illustrated in Figure 1, comprising a classical example of the following molecular subtypes of breast cancer: luminal A subtype (Figure 1, L1 to L7), basal-like subtype (Figure 1, B1 to B7) and HER-2-overexpressing subtype (Figure 1, H1 to $\mathrm{H} 7$ ). Strong immunoexpression of FOXA 1 and GATA-3 in the nuclei of malignant cells, as well as in some luminal epithelial cells from adjacent normal ducts, is shown in Figure 1 (L3 and L4). FOXA1 was positive (score $\geq 4$ ) in the nuclei of $42 \%$ (93 out of 224) of the invasive carcinomas, while GATA-3 was detected in $48 \%$ (97 out of 204) of the cases.

\section{Association between FOXA1 and GATA-3 expression and clinicopathological features and biological markers} The expression of FOXA1 was inversely associated with tumour size $(P=0.005)$, Nottingham Prognostic Index $(P=$ $0.002)$, histological grade $(P=0.001)$, vascular invasion $(P=$ $0.012)$, lymph node stage $(P=0.022)$ and HER-2 overexpression $(P=0.017)$, and was directly associated with $\mathrm{ER} \alpha$ expression $(P<0.0001)$ and $\mathrm{PR}$ expression $(P<0.0001)$. GATA-3 expression showed an inverse association with histological grade $(P=0.013)$ and HER-2 overexpression $(P<$ $0.0001)$, and a direct association with ER $\alpha$ expression $(P<$ $0.001)$ and $\mathrm{PR}$ expression $(P<0.001)$ (Table 2).

When we compared the expression of FOXA1 and GATA-3 with the molecular subtype, we found that $83.1 \%$ and $87.7 \%$ of FOXA1 and GATA-3, respectively, were comprised in the luminal A subtype $(P<0.0001)$ (Table 3 and Figure $1, L 1$ to L7). Basal-like subtype tumours were negative for FOXA1 (Figure 1, B3) and for GATA-3 (Figure 1, B4) in $85.7 \%$ and $84.6 \%$ of the cases, respectively (Table 3 ).

The immunohistochemical evaluation of FOXA1 and GATA-3 in breast tumour samples revealed that in 201 of interpretable cases a very significant direct association between the expression of FOXA1 and GATA-3 was observed $(P<0.0001)$ (Table 3).

On the evaluation of these two transcription factors with other important immunohistochemical markers in breast cancer, we found a strong inverse association with basal-like phenotype markers - namely, CK14 $(P=0.007, P=0.0002)$, CK5 $(P=$ $0.027, P<0.0001)$, vimentin $(P=0.003, P=0.0006)$ and $P$ cadherin $(P=0.012, P<0.0001)$ for FOXA1 and GATA-3, respectively. GATA-3, but not FOXA1, showed an interesting inverse association with EGFR $(P=0.001)$ (Table 3). 

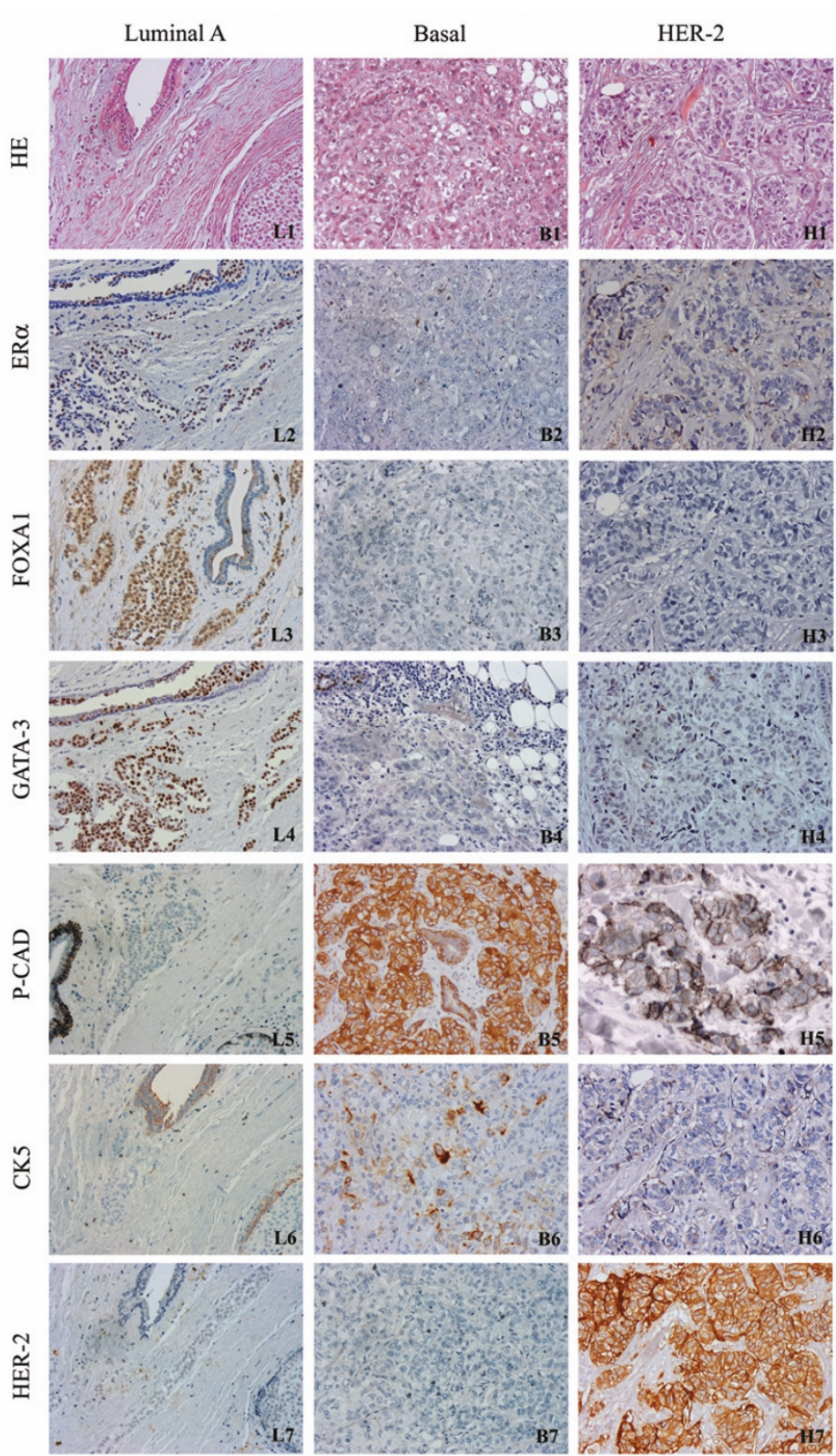

Immunohistochemistry panel showing differential expression pattern of FOXA1 and GATA-3. An example of luminal A (L1 to L7), basal-like (B1 to B7) and human epidermal growth factor receptor 2 (HER-2)-overexpressing ( $\mathrm{H} 1$ to $\mathbf{H} 7$ ) invasive breast tumours. Expression of the most commonly used breast cancer markers is also illustrated for comparison with the forkhead box A1 (FOXA1) and GATA binding protein 3 (GATA-3) expression. $(\mathrm{L} 1, \mathrm{~B} 1, \mathrm{H} 1)$ Haematoxylin-eosin stainings from each of the selected core cases. (L3, L4) Strong and restricted nuclear expression of FOXA1 and GATA-3 in the normal breast duct (internal control) and in the luminal A invasive tumour (grade II). (B3, B4) Negative expression of FOXA1 and GATA-3 in basal subtype tumour (grade III). (H3, H4) HER-2-overexpressing tumour showing negativity for FOXA1 and GATA-3 expression (grade III). All microscopy images are at $40 \times$ magnification. ER, oestrogen receptor; P-CAD, P-cadherin; CK, cytokeratin.

\section{Survival and patient outcome analysis}

Kaplan-Meier survival curves demonstrate that patients with FOXA1-positive breast carcinomas showed a significant difference towards the longer disease-free survival time $(P<$ 0.001 ; Figure 2a). Although these are no statistically significant differences in survival according to GATA-3 expression
$(P=0.055$; Figure $2 b)$, the positivity for this marker is also associated with a better outcome for breast cancer patients.

As previously demonstrated in other studies, univariate Cox proportional hazard analysis showed that the tumour size, lymph node stage, tumour grade, as well as the expression of $E R, P R$ and HER-2 were significant predictors for disease-free 
Table 2

\begin{tabular}{|c|c|c|c|c|c|c|c|c|}
\hline Variable & $N$ & $\begin{array}{l}\text { FOXA1-negative } \\
(\%)\end{array}$ & $\begin{array}{l}\text { FOXA1-positive } \\
(\%)\end{array}$ & $P$ value & $n$ & $\begin{array}{l}\text { GATA3-negative } \\
(\%)\end{array}$ & $\begin{array}{l}\text { GATA3-positive } \\
(\%)\end{array}$ & $P$ value \\
\hline Tumour size (mm) & 209 & $35.2 \pm 24.0(126)$ & $26.8 \pm 15.7(83)$ & 0.005 & 191 & $34.4 \pm 25.2(100)$ & $28.6 \pm 16.7(91)$ & 0.064 \\
\hline $\begin{array}{l}\text { Lymphovascular } \\
\text { invasion }\end{array}$ & 203 & & & & 185 & & & \\
\hline Present & 97 & $67(69.1)$ & $30(30.9)$ & 0.012 & 92 & 49 (53.3) & $43(46.7)$ & 0.829 \\
\hline Absent & 106 & $55(51.9)$ & $51(48.1)$ & & 93 & $51(54.8)$ & $42(45.2)$ & \\
\hline Lymph node stage & 203 & & & & 185 & & & \\
\hline Negative & 106 & $55(51.9)$ & $51(48.1)$ & 0.022 & 93 & $51(54.8)$ & $42(45.2)$ & 0.166 \\
\hline 1 to 3 lymph nodes & 49 & $31(63.3)$ & $18(36.7)$ & & 46 & $20(43.5)$ & $26(56.5)$ & \\
\hline$>3$ lymph nodes & 48 & $36(75)$ & $12(25)$ & & 46 & $29(63)$ & $17(37)$ & \\
\hline Grade & 224 & & & & 204 & & & \\
\hline Grade I & 44 & $25(56.8)$ & $19(43.2)$ & 0.001 & 40 & $24(60)$ & $16(40)$ & 0.013 \\
\hline Grade II & 105 & $50(47.6)$ & $55(52.4)$ & & 96 & $40(41.7)$ & $56(58.3)$ & \\
\hline Grade III & 75 & $56(74.7)$ & $19(25.3)$ & & 68 & $43(63.2)$ & $25(36.8)$ & \\
\hline Histology & 224 & & & & 204 & & & \\
\hline IDC & 188 & $113(60.1)$ & 75 (39.9) & 0.119 & 171 & $91(53.2)$ & $80(46.8)$ & 0.104 \\
\hline ILC & 6 & 2 (33.3) & $4(66.7)$ & & 6 & $0(0)$ & $6(100)$ & \\
\hline Tubular & 1 & $1(100)$ & $0(0)$ & & 1 & $0(0)$ & $1(100)$ & \\
\hline Medullary & 7 & $5(71.4)$ & $2(28.6)$ & & 7 & $5(71.4)$ & $2(28.6)$ & \\
\hline Other & 19 & 7 (36.8) & $12(63.2)$ & & 16 & $9(56.2)$ & $7(43.8)$ & \\
\hline Mixed & 3 & $3(100)$ & $0(0)$ & & 3 & $2(66.7)$ & 1 (33.3) & \\
\hline $\begin{array}{l}\text { Nottingham } \\
\text { Prognostic Index }\end{array}$ & 190 & & & & 172 & & & \\
\hline$<3.4$ & 44 & $18(40.9)$ & $26(59.1)$ & 0.002 & 40 & $19(47.5)$ & $21(52.5)$ & 0.293 \\
\hline 3.4 to 5.4 & 96 & $59(61.5)$ & 37 (38.5) & & 86 & $44(51.2)$ & $42(48.8)$ & \\
\hline$>5.4$ & 50 & $38(76)$ & $12(24)$ & & 46 & $29(63)$ & 17 (37) & \\
\hline $\mathrm{ER} \alpha$ & 224 & & & & 204 & & & \\
\hline Positive & 133 & $60(45.1)$ & $73(54.9)$ & $<0.0001$ & 122 & 41 (33.6) & $81(66.4)$ & $<0.0001$ \\
\hline Negative & 91 & $71(78)$ & $20(22)$ & & 82 & $66(80.9)$ & $16(19.5)$ & \\
\hline PR & 223 & & & & 204 & & & \\
\hline Positive & 83 & 33 (39.7) & $50(60.3)$ & $<0.0001$ & 74 & $22(29.7)$ & 52 (70.3) & $<0.0001$ \\
\hline Negative & 140 & $98(70)$ & $42(30)$ & & 130 & $85(65.4)$ & 45 (34.6) & \\
\hline HER-2 & 220 & & & & 201 & & & \\
\hline Positive & 35 & $27(77.1)$ & 8 (22.9) & 0.017 & 34 & 29 (85.3) & 5 (14.7) & $<0.0001$ \\
\hline Negative & 185 & $103(55.7)$ & $82(44.3)$ & & 167 & $77(46.1)$ & $90(53.9)$ & \\
\hline
\end{tabular}

FOXA-1, forkhead box A1; GATA-3, GATA binding protein 3; IDC, invasive ductal carcinoma (not otherwise specified); ILC, invasive lobular carcinoma; ER $\alpha$, oestrogen receptor; PR, progesterone receptor; HER-2, human epidermal growth factor receptor 2. 
Table 3

\begin{tabular}{|c|c|c|c|c|c|c|c|c|}
\hline Variable & $N$ & FOXA1-negative (\%) & FOXA1-positive (\%) & $P$ value & $n$ & GATA3-negative (\%) & GATA3-positive (\%) & $P$ value \\
\hline EGFR & 223 & & & & 203 & & & \\
\hline Positive & 13 & $10(7.6)$ & 3 (3.3) & 0.171 & 11 & $11(10.4)$ & $0(0)$ & 0.001 \\
\hline Negative & 210 & $121(92.4)$ & $89(96.7)$ & & 192 & $95(89.6)$ & $97(100)$ & \\
\hline P-cadherin & 220 & & & & 202 & & & \\
\hline Positive & 75 & $53(40.8)$ & $22(24.4)$ & 0.012 & 71 & $52(49.1)$ & $19(19.8)$ & $<0.0001$ \\
\hline Negative & 145 & $77(59.2)$ & $68(75.6)$ & & 131 & $54(50.9)$ & $77(80.2)$ & \\
\hline Cytokeratin 5 & 224 & & & & 204 & & & \\
\hline Positive & 50 & $36(27.5)$ & $14(15)$ & 0.027 & 48 & $39(36.4)$ & $9(9.3)$ & $<0.0001$ \\
\hline Negative & 174 & $95(72.5)$ & $79(85)$ & & 156 & $68(63.6)$ & $88(90.7)$ & \\
\hline Cytokeratin 14 & 219 & & & & 201 & & & \\
\hline Positive & 14 & $13(10.1)$ & $1(1.5)$ & 0.007 & 14 & 14 (13.3) & $0(0)$ & 0.0002 \\
\hline Negative & 205 & $116(89.9)$ & $89(98.9)$ & & 187 & $91(86.7)$ & $96(100)$ & \\
\hline Vimentin & 203 & & & & 194 & & & \\
\hline Positive & 34 & $28(23.1)$ & $6(7.3)$ & 0.003 & 32 & $26(25)$ & $6(6.7)$ & 0.0006 \\
\hline Negative & 169 & $93(76.9)$ & $76(92.7)$ & & 162 & $78(75)$ & 84 (93.3) & \\
\hline FOXA1 & - & - & - & - & 201 & & & \\
\hline Positive & - & - & - & & 82 & $16(15.4)$ & $66(68)$ & $<0.0001$ \\
\hline Negative & - & - & - & & 119 & $88(84.6)$ & 31 (32) & \\
\hline GATA-3 & 201 & & & & - & - & - & - \\
\hline Positive & 97 & $31(26.1)$ & $66(80.5)$ & $<0.0001$ & - & - & - & \\
\hline Negative & 104 & $88(73.9)$ & $16(19.5)$ & & - & - & - & \\
\hline Subtype & 202 & & & & 187 & & & \\
\hline Luminal A & 125 & $56(47)$ & $69(83.1)$ & $<0.0001$ & 114 & $36(36.7)$ & $78(87.7)$ & $<0.0001$ \\
\hline Luminal B & 8 & $4(3.4)$ & $4(4.8)$ & & 8 & $5(5.1)$ & $3(3.4)$ & \\
\hline HER-2 & 27 & $23(19.3)$ & $4(4.8)$ & & 26 & $24(24.5)$ & $2(2.2)$ & \\
\hline Basal & 42 & 36 (30.3) & $6(7.3)$ & & 39 & 33 (33.7) & $6(6.7)$ & \\
\hline
\end{tabular}

FOXA-1, forkhead box A1; GATA-3, GATA binding protein 3; EGFR, epidermal growth factor receptor; HER-2, human epidermal growth factor receptor 2.

survival. In accordance with the trend shown by the KaplanMeier curves, the expression of FOXA1 was also a significant predictor for disease-free survival, showing that negative cases carry a fourfold increased risk of recurrence (hazard ratio $=4.25,95 \%$ confidence interval $=1.76$ to 10.28 ) when compared with the positive ones. In contrast, GATA-3 expression was revealed not to be important as a predictive marker for better outcome in this series (hazard ratio $=1.97,95 \%$ confidence interval $=0.96$ to 4.01 ) (Table 4).

Prognostic significance of FOXA1 and GATA-3 expression in ER-negative breast cancer

Several studies have shown that FOXA1 and GATA-3 expression are strong predictors of better clinical outcome in breast tumours and are among the best predictors of ER $\alpha$-positive status [9-12,26,31,33,34]. Since FOXA1 and GATA-3 show an intrinsic high correlation between themselves and with $\mathrm{ER} \alpha$ status, however, the prognostic and predictive value of these markers may simply reflect this high expression association. A cohort of ER $\alpha$-negative patients was therefore studied in order to evaluate the predictive importance of FOXA1 and GATA-3 expression in this subset of breast carcinomas.

When the association analysis was performed in the subset of ER $\alpha$-negative patients, FOXA1 and GATA-3 failed to show any significant association with the studied clinicopathological features. Analysing the association of these transcription factors with the immunohistochemical biomarkers in breast can- 
Figure 2
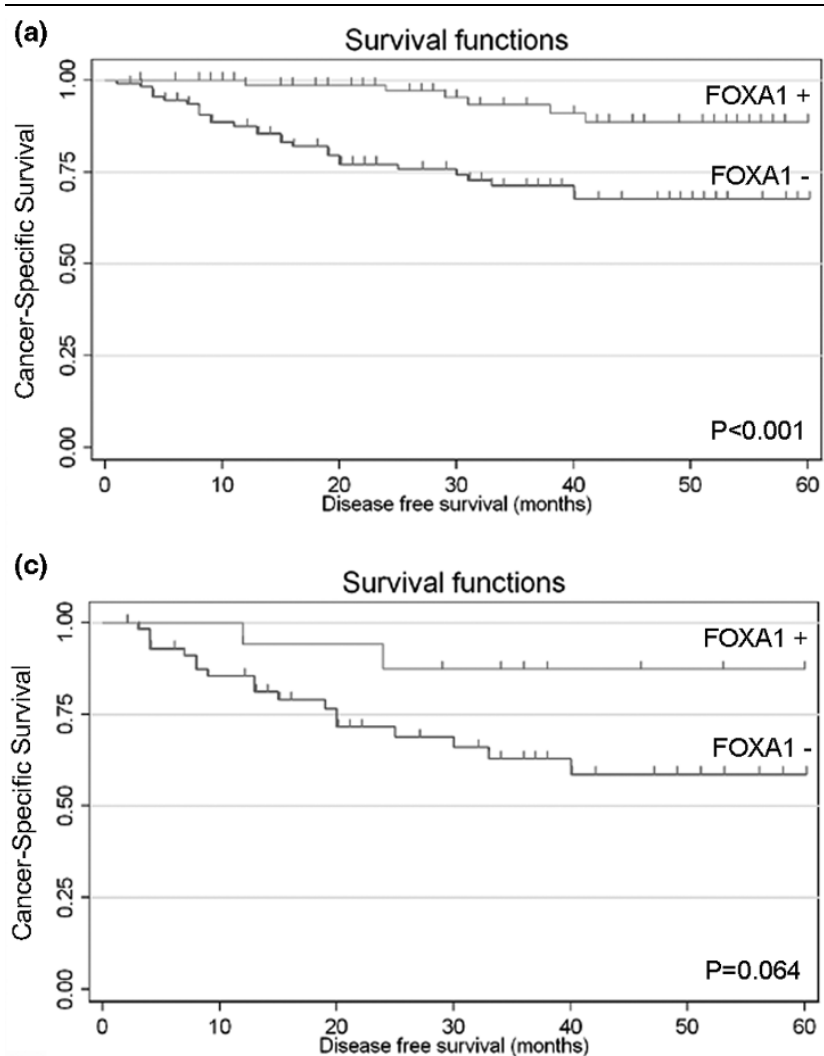

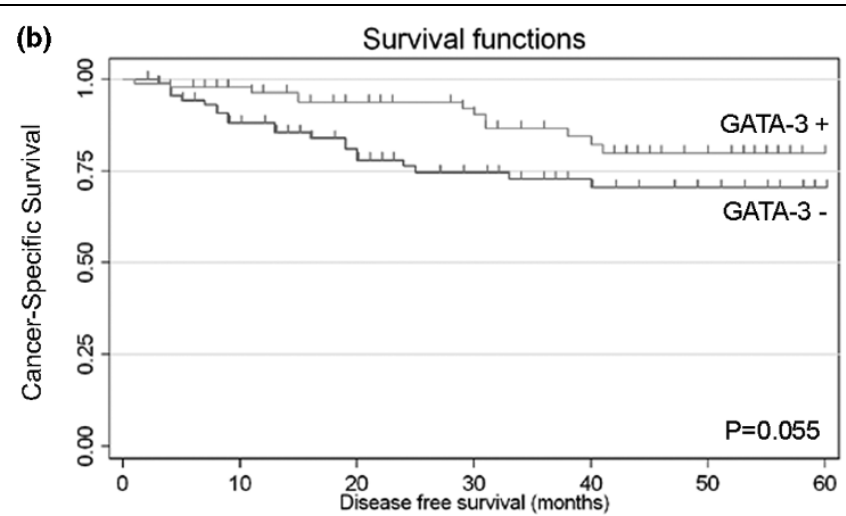

(d)

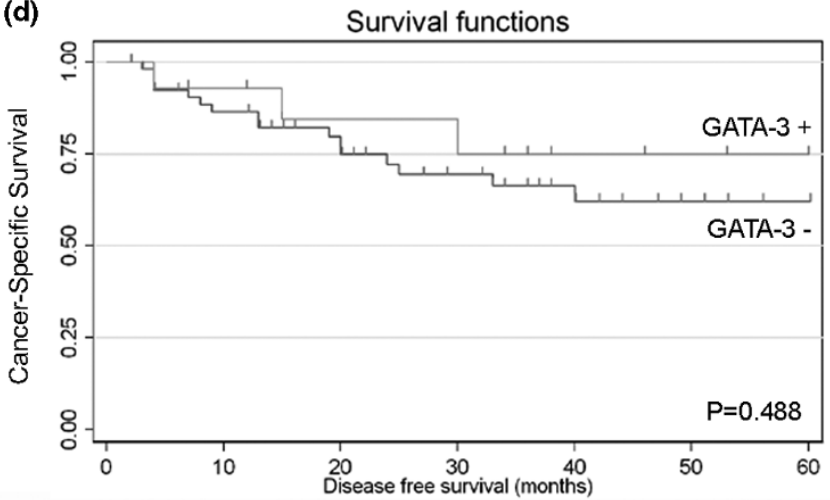

Kaplan-Meier survival curves for disease-free survival. (a) Survival functions for forkhead box A1 (FOXA1) in the whole breast cancer patient series $(P<0.001)$. (b) Survival functions for GATA binding protein 3 (GATA-3) in the whole breast cancer patient series $(P=0.055)$. (c) Survival functions for FOXA1 in the oestrogen receptor $\alpha$-negative breast cancer patient cohort $(P=0.064)$. (d) Survival functions for GATA-3 in the oestrogen receptor $\alpha$-negative breast cancer patient cohort $(P=0.488)$.

cer, no significant associations were found concerning FOXA1 expression. GATA-3 negativity, however, showed significant association with P-cadherin and CK14 expression. Although not statistically significant, we also observed a trend towards the association of GATA-3 with the other studied basal-like phenotype markers (namely, EGFR, CK5 and vimentin), where the majority of the negative cases for GATA-3 are positive for those proteins (Table 5).

In this subset of ER $\alpha$-negative patients, however, an association between loss of FOXA1 expression and worst diseasefree survival was found $(P=0.064)$, in contrast with GATA-3 expression $(P=0.488$ ) (Figure $2 c$ and $2 d$, respectively). Moreover, in order to quantify the risk of these survival associations, univariate analysis was performed for FOXA1 and GATA-3 as well as for the classical prognostic factors in breast cancer. In line with the Kaplan-Meier curves, GATA-3 negativity does not account for an increased risk of recurrence in ER $\alpha$-negative tumours. FOXA1 expression, however, is able to stratify this relative risk among this subset of carcinomas, since its loss accounts for a 3.61-fold increased risk for breast cancer recurrence (Table 6). These results suggest a protective role for this forkhead protein in this poor-outcome breast cancer subgroup.

Additionally, the multivariate Cox hazard analysis, with models including tumour size and lymph vascular invasion, demonstrates the independent value of FOXA1 expression as a predictor of patient outcome in ER $\alpha$-negative tumours. FOXA1 negativity is strongly related to breast cancer recurrence, this association being very close to statistical significance (FOXA1-negative vs. FOXA1-positive: hazard ratio $=7.02$, $95 \%$ confidence interval $=0.92$ to $53.37 ; P=0.060)$. This analysis also confirmed that GATA-3 expression is not an important predictor of breast cancer recurrence in ER $\alpha$-negative carcinomas (GATA-3-negative vs. GATA-3-positive patients: hazard ratio $=1.46,95 \%$ confidence interval $=0.40$ to $5.29 ; P=0.559$ ).

\section{Discussion}

Several studies of global gene expression revealed high levels of FOXA1 often associated with the expression of ER $\alpha$ $[6,35,36]$. In addition, other gene whose expression has been highly correlated with $\mathrm{ER} \alpha$ in breast cancer encodes the transcription factor GATA-3 $[6,11,26,27]$. Indeed, FOXA1, GATA- 
Table 4

\begin{tabular}{|c|c|c|c|}
\hline Variable & Evaluation & Hazard ratio (95\% confidence interval) & $P$ value \\
\hline \multirow[t]{3}{*}{ Tumour size } & $\mathrm{T} 1(\leq 2 \mathrm{~mm})$ & 1 & \\
\hline & $\mathrm{T} 2(2<\mathrm{T} \leq 5 \mathrm{~mm})$ & $1.57(0.70$ to 3.51$)$ & 0.265 \\
\hline & ТЗ $(>5 \mathrm{~mm})$ & $3.12(1.16$ to 8.41$)$ & 0.024 \\
\hline \multirow[t]{3}{*}{ Lymph node stage } & Negative & 1 & \\
\hline & 1 to 3 lymph nodes & $0.56(0.20$ to 1.56$)$ & 0.272 \\
\hline & $>3$ lymph nodes & $2.68(1.30$ to 5.49$)$ & 0.007 \\
\hline \multirow[t]{3}{*}{ Tumour grade } & Grade I & 1 & \\
\hline & Grade II & $2.60(0.58$ to 11.56$)$ & 0.208 \\
\hline & Grade III & 7.65 (1.80 to 32.48$)$ & 0.006 \\
\hline \multirow[t]{2}{*}{ ER expression } & ER-positive & 1 & \\
\hline & ER-negative & $2.94(1.52$ to 5.57$)$ & 0.001 \\
\hline \multirow[t]{2}{*}{ PR expression } & PR-positive & 1 & \\
\hline & PR-negative & $2.16(1.04$ to 4.46$)$ & 0.038 \\
\hline \multirow[t]{2}{*}{ HER-2/neu expression } & HER-2/neu-negative & 1 & \\
\hline & HER-2/neu-positive & $2.47(1.19$ to 5.09$)$ & 0.014 \\
\hline \multirow[t]{2}{*}{ FOXA1 expression } & FOXA1-positive & 1 & \\
\hline & FOXA1-negative & $4.25(1.76$ to 10.28$)$ & 0.001 \\
\hline \multirow[t]{2}{*}{ GATA-3 expression } & GATA-3-positive & 1 & \\
\hline & GATA-3-negative & 1.97 (0.96 to 4.01$)$ & 0.061 \\
\hline
\end{tabular}

ER, oestrogen receptor; FOXA-1, forkhead box A1; GATA-3, GATA binding protein 3; HER-2, human epidermal growth factor receptor 2; PR, progesterone receptor.

3 and ER $\alpha$ form a transcriptional circuit required for growth, differentiation and hormonal dependency of the lineage of mammary luminal cells [22,37]. Previous work using immunohistochemistry has shown that the expression of FOXA1 $[10,31,33]$ and of GATA-3 $[9,34,37]$ is in close association with ER $\alpha$ expression in breast cancer, highlighting their prognostic and predictive value in this malignancy. In fact, since these three proteins are components of a transcriptional network that dictates the phenotype of hormonal-dependent breast cancer [37], the study of their expression would improve our understanding of the ER $\alpha$, FOXA1 and GATA-3 relationship in breast cancer patients.

In the present study the staining pattern of FOXA1 and GATA3 in normal breast tissue is strikingly similar to that of $E R \alpha$, which suggests the same cellular co-localization of these three cross-functional proteins. In the studied series, the expression of FOXA1 was inversely associated with clinicopathological features - namely, with tumour size, tumour grade, Nottingham Prognostic Index, lymph vascular invasion, lymph node stage and HER-2 overexpression - while its expression was directly associated with ER $\alpha, P R$ and the luminal A subtype. Thorat and colleagues, in a recent published study of 139 cases, did not demonstrate a significant association with tumour size, lymph node status or HER-2 [31]. Moreover, these authors also found an inverse association between FOXA1 and basallike phenotype markers (namely, CK5 and CK14). Importantly, in our study we reinforced this inverse association between FOXA1 expression and the expression of P-cadherin or vimentin.

The requirement of this forkhead for optimal expression of at least $50 \%$ of ER $\alpha$-regulated genes and oestrogen-induced proliferation was recently described [13], and our and other results may just represent the strong regulatory interdependency between ER $\alpha$ and FOXA1. Since ER $\alpha$ is one of the central genes for the regulation of growth/proliferation of mammary epithelia, and for the hormone-responsive phenotype of breast tumours [9], FOXA1 appears an important biological-regulatory factor with prognostic consequences in this setting. In fact, in the present study, FOXA1 expression was shown to be an important predictor of disease-free survival, in addition to the robust association with clinicopathological features. Interestingly, univariate analysis showed that the evaluation of FOXA1 expression has an important value in the assessment of the prognostic risk for breast cancer patient 
Table 5

\begin{tabular}{|c|c|c|c|c|c|c|c|c|}
\hline Variable & $n$ & $\begin{array}{l}\text { FOXA1-negative } \\
(\%)\end{array}$ & FOXA1-positive (\%) & $P$ value & $n$ & $\begin{array}{l}\text { GATA3-negative } \\
(\%)\end{array}$ & GATA3-positive (\%) & $P$ value \\
\hline Tumour size & 80 & $36.7 \pm 24.2(65)$ & $36.6 \pm 24.8(15)$ & 0.987 & 74 & $34.46 \pm 23.6(60)$ & $43.4 \pm 27.4(14)$ & 0.229 \\
\hline $\begin{array}{l}\text { Lymphovascular } \\
\text { invasion }\end{array}$ & 83 & & & & 78 & & & \\
\hline Present & 35 & $29(82.8)$ & $6(17.2)$ & 0.391 & 35 & $29(82.8)$ & $6(17.2)$ & 0.867 \\
\hline Absent & 48 & $36(75)$ & $12(25)$ & & 43 & $35(81.4)$ & $8(18.6)$ & \\
\hline Lymph node stage & 83 & & & & 78 & & & \\
\hline Negative & 48 & $36(75)$ & $12(25)$ & 0.456 & 43 & $35(81.4)$ & $8(18.6)$ & 0.609 \\
\hline $\begin{array}{l}1 \text { to } 3 \text { lymph } \\
\text { nodes }\end{array}$ & 12 & $11(91.7)$ & $1(8.3)$ & & 12 & $11(91.7)$ & $1(8.3)$ & \\
\hline$>3$ lymph nodes & 23 & 18 (78.3) & $5(21.7)$ & & 23 & $18(78.3)$ & $5(21.7)$ & \\
\hline Grade & 87 & & & & 80 & & & \\
\hline Grade I & 8 & $6(75)$ & $2(25)$ & 0.166 & 8 & $8(100)$ & $0(0)$ & 0.366 \\
\hline Grade II & 33 & $23(69.7)$ & $10(30.3)$ & & 28 & $22(78.6)$ & $6(21.4)$ & \\
\hline Grade III & 46 & $40(86.9)$ & $6(13.1)$ & & 44 & $36(81.8)$ & $8(18.2)$ & \\
\hline $\begin{array}{l}\text { Nottingham } \\
\text { Prognostic Index }\end{array}$ & 76 & & & & 71 & & & \\
\hline$<3.4$ & 11 & $9(81.8)$ & $2(18.2)$ & 0.982 & 10 & $9(90)$ & $1(10)$ & 0.615 \\
\hline 3.4 to 5.4 & 34 & $27(79.4)$ & $7(20.6)$ & & 32 & 26 (81.3) & $6(18.7)$ & \\
\hline$>5.4$ & 31 & $25(80.6)$ & $6(19.4)$ & & 29 & $22(75.8)$ & $7(24.2)$ & \\
\hline HER-2 & 85 & & & & 79 & & & \\
\hline Positive & 26 & $23(88.5)$ & $3(11.5)$ & 0.254 & 26 & 24 (92.3) & $2(7.7)$ & 0.102 \\
\hline Negative & 59 & $46(77.9)$ & $13(22.1)$ & & 53 & $41(77.4)$ & $12(22.6)$ & \\
\hline EGFR & 86 & & & & 80 & & & \\
\hline Positive & 12 & 10 (83.3) & $2(16.7)$ & 0.771 & 11 & $11(100)$ & $0(0)$ & 0.100 \\
\hline Negative & 74 & $59(79.7)$ & 15 (20.3) & & 69 & $55(79.7)$ & $14(20.3)$ & \\
\hline P-cadherin & 87 & & & & 80 & & & \\
\hline Positive & 53 & $45(84.9)$ & $8(15.1)$ & 0.107 & 52 & $47(90.4)$ & $5(9.6)$ & 0.011 \\
\hline Negative & 34 & $24(70.6)$ & $10(29.4)$ & & 28 & $19(67.8)$ & $9(32.2)$ & \\
\hline Cytokeratin 5 & 87 & & & & 80 & & & \\
\hline Positive & 33 & $28(84.8)$ & $5(15.2)$ & 0.318 & 32 & $29(90.6)$ & $3(9.4)$ & 0.118 \\
\hline Negative & 54 & $41(75.9)$ & $13(24.1)$ & & 48 & $37(77.1)$ & $11(22.9)$ & \\
\hline Cytokeratin 14 & 85 & & & & 78 & & & \\
\hline Positive & 14 & $13(92.8)$ & $1(7.2)$ & 0.188 & 14 & $14(100)$ & $0(0)$ & 0.053 \\
\hline Negative & 71 & 55 (77.5) & $16(22.5)$ & & 64 & $50(78.1)$ & $14(21.9)$ & \\
\hline Vimentin & 82 & & & & 75 & & & \\
\hline Positive & 27 & $25(92.6)$ & $2(7.4)$ & 0.074 & 25 & $24(96)$ & $1(4)$ & 0.064 \\
\hline Negative & 55 & $42(76.4)$ & $13(23.6)$ & & 50 & $40(80)$ & $10(20)$ & \\
\hline FOXA1 & - & & & & 78 & & & \\
\hline Positive & - & - & - & - & 15 & $6(40)$ & $9(60)$ & $<0.0001$ \\
\hline Negative & - & - & - & & 63 & $58(92.1)$ & $5(7.9)$ & \\
\hline GATA-3 & 78 & & & & - & & & \\
\hline Positive & 14 & 5 (35.7) & 9 (64.3) & $<0.0001$ & - & - & - & - \\
\hline Negative & 64 & $58(90.6)$ & $6(9.4)$ & & - & - & - & \\
\hline
\end{tabular}

ER, oestrogen receptor; EGFR, epidermal growth factor receptor; FOXA-1, forkhead box A1; GATA-3, GATA binding protein 3; HER-2, human epidermal growth factor receptor 2 . 
Table 6

\begin{tabular}{|c|c|c|c|}
\hline Variable & Evaluation & Hazard ratio (95\% confidence interval) & $P$ value \\
\hline \multirow[t]{3}{*}{ Tumour size } & $\mathrm{T} 1(\leq 2 \mathrm{~mm})$ & 1 & \\
\hline & $\mathrm{T} 2(2<\mathrm{T} \leq 5 \mathrm{~mm})$ & $1.45(0.40$ to 5.21$)$ & 0.567 \\
\hline & ТЗ $(>5 \mathrm{~mm})$ & $3.57(0.88$ to 14.4$)$ & 0.073 \\
\hline \multirow[t]{3}{*}{ Lymph node stage } & Negative & 1 & \\
\hline & 1 to 3 lymph nodes & $0.47(0.10$ to 2.16$)$ & 0.338 \\
\hline & $>3$ lymph nodes & 2.49 (1.02 to 6.03$)$ & 0.044 \\
\hline \multirow[t]{3}{*}{ Tumour grade } & Grade I & a & \\
\hline & Grade II & 1 & \\
\hline & Grade III & 2.85 (1.05 to 7.57$)$ & 0.040 \\
\hline \multirow[t]{2}{*}{ HER-2/neu expression } & HER-2/neu-negative & 1 & \\
\hline & HER-2/neu-positive & $2.04(0.90$ to 4.61$)$ & 0.086 \\
\hline \multirow[t]{2}{*}{ FOXA1 expression } & FOXA1-positive & 1 & \\
\hline & FOXA1-negative & $3.61(0.83$ to 15.60$)$ & 0.086 \\
\hline \multirow[t]{2}{*}{ GATA-3 expression } & GATA-3-positive & 1 & \\
\hline & GATA-3-negative & $1.53(0.44$ to 5.28$)$ & 0.495 \\
\hline
\end{tabular}

FOXA-1, forkhead box A1; GATA-3, GATA binding protein 3; HER-2, human epidermal growth factor receptor 2. aThere were no oestrogenreceptor-negative cases classified as grade I among the patients with available follow-up information.

recurrence, with a magnitude of association similar to the observed for the classical prognostic factors, such as tumour size and lymph node stage, tumour grade, and ER and HER-2 expression. This finding is in line with previously published works, where both Badve and colleagues and Habashy and colleagues also demonstrated that FOXA1 expression is able to significantly predict a better survival for breast cancer patients $[10,33]$, although the multivariate analysis showed that it is not an independent prognostic marker, exactly as shown for ER. These studies still suggest that ER $/$ FOXA1expressing cells, after acquiring tumorigenicity, may promote selective clonal expansion, resulting in a specific subtype of breast cancer - the luminal subtype A. Thorat and colleagues also suggested that FOXA1 immunohistochemistry may be used as a marker for tumours pertaining to luminal subtype $A$ breast cancer, which has an exceptionally good prognosis [31].

In contrast to FOXA1, GATA-3 failed the association with most of the clinicopathological features - the exception being an inverse association with HER-2 expression and tumour histological grade, although it was also directly associated with $E R \alpha$ and PR expression, as well as with tumours from the luminal A subtype. These results are partially in line with previous work from Mehra and colleagues, which found that low levels of GATA-3 expression were associated with higher tumour histological grade, positive lymph nodes, larger tumour size, negative ER expression and HER-2 overexpression [24]. In the present study we could not find an association between GATA-3 expression and lymph node status, in agreement with a recent cohort study from Voduc and colleagues comprising more than 3,000 invasive breast cancers [34]. Regarding the association between GATA-3 and ER $\alpha, 66 \%$ of the cases coexpressed these markers - which is a larger percentage than those previously described by Mehra and colleagues (46\%) and by Voduc and colleagues (39\%) [24,34].

Through the analysis of Kaplan-Meier survival curves it was not possible to demonstrate a significant association between GATA-3 expression and disease-free survival in this breast cancer series, which is in accordance with data from the large cohort study of Voduc and colleagues [34]. The univariate analysis confirmed this observation, although there is an association between the positivity for this marker and the better outcome for breast cancer patients.

Interestingly, the strength of the inverse association that was observed between GATA-3 and basal-like markers - namely, CK5, CK14, vimentin, EGFR and P-cadherin - suggests that GATA-3 can be important for the differentiation state of the malignant cells, where its presence, together with other differentiation involved partners, may drive the luminal profile of a malignant cell population within the tumour. Actually, this growth and differentiation role for GATA-3 in normal mammary 
epithelial cells has been already widely described $[9,22,34,38]$. Moreover, GATA-3-induced genes were found in the luminal cluster of gene expression studies, highlighting its putative ability to maintain a luminal differentiated phenotype [34].

In the past, several studies have shown that FOXA1 expression and GATA-3 expression are among the best predictors of ER $\alpha$-positive status [9-12,26,31,33,34]. Additionally, some reports have proven that FOXA1 expression is able to significantly differentiate patients with a better survival within the luminal A subgroup, or even within the ER $\alpha$-positive cohort (including luminal $A$ and luminal $B$ subtypes) [10,31]. These authors claim that FOXA1 can serve as a clinical marker for the luminal $A$ subtype, and that its prognostic ability in these lowrisk breast cancers may prove to be useful in clinical treatment decisions. In contrast, Habashy and colleagues did not find any clinical relevance in the immunohistochemical assessment of FOXA1 in breast cancer routine practice [33], since it was not able to stratify ER-positive (luminal-like) tumours into clinically significant subgroups.

Although never assessed, the difference between these studies can be possibly due to the endocrine and chemotherapy administered to the different series of patients, which can block the ER $\alpha$-associated pathways and confound interpretation of the results. Moreover, since ER $\alpha$, FOXA1 and GATA-3 show an intrinsic high correlation between themselves, the prognostic and predictive values of these markers may simply reflect this high expression association and the described biological interactions.

In order to study whether there was a prognostic value for the expression of these two transcription factors in the absence of ER $\alpha$ expression, we therefore decided to perform an exploratory subgroup analysis in a cohort of ER $\alpha$-negative patients. The aim was to test, for the first time, the possible utility of FOXA1 and/or GATA-3 as classifiers for breast cancer recurrence in this high-risk subset of patients, revealing a stratification of ER-negative tumours with different biological behaviours. Interestingly, only FOXA1-positive expression showed a clear protective effect for breast cancer relapse in this cohort of patients with poor prognosis. Patients with loss of FOXA1 tumour expression showed an increased risk for breast cancer recurrence compared with the patients that were positive for this marker. The relative risk estimate was higher than that calculated for HER-2 positivity, which is a well-known prognostic factor in hormone-independent breast carcinomas. Moreover, the multivariate analysis, including the tumour size and lymph node status, demonstrated the independent value of FOXA1 as a predictor of patient outcome in ER $\alpha$-negative tumours.

In conclusion, our results confirmed the strong association between ER $\alpha$ and FOXA1 in breast cancer and confirmed the role of FOXA1 as a significant breast cancer predictor of good outcome in univariate analysis, directly associated with luminal A and inversely associated with basal-like subtype of breast cancer. GATA-3 was neither a predictor for breast cancer disease-free survival nor a prognostic marker, but was shown to be an important and robust luminal differentiation marker, even stronger than FOXA1. Based on these findings, the expression assessment of FOXA1 and GATA-3 in breast cancer patients can provide important clinical information - not only regarding the favourable prognostic nature and tumour behaviour, but the expression can also constitute an important tool to define and assess the luminal A subtype in breast cancer. We demonstrated that FOXA1 expression also has an important role as breast cancer predictor of good outcome in ERnegative breast carcinomas.

Based on our results, we can consider that the expression of FOXA1, as an ER-associated gene, may be important to the hormone-responsive phenotype of breast cancer, regardless of the tumour ER status. The absence of FOXA1 in luminal/ERpositive breast cancer patients may contribute to identify the $30 \%$ of ER-positive tumours that are not hormone responsive. Additionally, because of the known cross-talk and functional network between FOXA1 and the regulation of ER $\alpha$ and its downstream targets, the expression of FOXA1 in ER-negative breast cancer patients may represent the existence of an alternative oestradiol-independent response pathway, which may allow the 5 to $15 \%$ of ER-negative tumours to become responsive to endocrine-driven therapies. The clinical implication of these findings requires a larger prospective cohort, especially to evaluate the value of FOXA1 in the therapeutic response setting. Nevertheless, the current study already represents an important step forward in the overview the ER-negative type of tumours, with putative future benefit for staging and treatment of these patients.

\section{Conclusions}

Current challenges in oncology include prediction of tumour behaviour and selection of effective therapy for individual treatment based on molecular targets. In breast cancer, ER $\alpha$ expression alone has been used to guide systemic therapy and to estimate patient prognosis. Not all ER-positive carcinomas, however, show comparable prognosis or react similarly to anti-hormonal therapy, and some ER-negative tumours curiously respond to therapy. This clinical evidence demonstrates that breast carcinomas are extremely heterogeneous, emphasizing the need for improving the molecular classification within tumours to better predict their clinical behaviour and the patient's response to current therapies.

The identification of transcription factors that control the ER $\alpha$ pathway provide an opportunity to identify specific subsets of patients that will have a good prognosis, as well as who will benefit from endocrine treatment. In the present work, we studied FOXA1 and GATA-3 expression in order to evaluate 
whether the proteins would predict the recurrence behaviour of breast cancer patients. We verified that patients harbouring FOXA1-positive and ER-negative tumours show a better disease-free survival, demonstrating the clinical importance of these two biomarkers in breast cancer molecular classification and prognosis. The analyses showed that FOXA1 and ER $\alpha$ should be used together in order to subclassify breast carcinomas and to predict the outcome of breast cancer patients.

\section{Competing interests}

The authors declare that they have no competing interests.

\section{Authors' contributions}

AA, BS, DV and NLo carried out all the immunoassays and general laboratory work. FM, VC and FS were the pathologists who revised and classified all cases. NLu, JB and SC performed the statistical analysis. AA and JP contributed to the conception and design, analysis and interpretation of data. AA, $J P, F M, E W L$ and FS were involved in drafting the manuscript and revising it critically for important intellectual content. All authors read and approved the final manuscript.

\section{Acknowledgements}

The present study was supported by a research grant (SFRH/BD/ $15316 / 2005$ to AA) financed by the Portuguese Science and Technology Foundation (FCT). The authors thank Prof. Raquel Seruca (coordinator from the Cancer Genetics group at IPATIMUP) for scientific assistance, Dr José Luis Costa (postdoctorate at IPATIMUP) for critically reading the manuscript before submission, and Dr Nuno Marcos (PhD student at IPATIMUP) for artwork assistance.

\section{References}

1. Knight WA 3rd, Osborne CK, Yochmowitz MG, McGuire WL: Steroid hormone receptors in the management of human breast cancer. Ann Clin Res 1980, 12:202-207.

2. Schneider J, Ruschhaupt M, Buness A, Asslaber M, Regitnig P, Zatloukal K, Schippinger W, Ploner F, Poustka A, Sultmann H: Identification and meta-analysis of a small gene expression signature for the diagnosis of estrogen receptor status in invasive ductal breast cancer. Int J Cancer 2006, 119:2974-2979.

3. Jordan VC, Wolf MF, Mirecki DM, Whitford DA, Welshons WV: Hormone receptor assays: clinical usefulness in the management of carcinoma of the breast. Crit Rev Clin Lab Sci 1988, 26:97-152.

4. Perou CM, Sorlie T, Eisen MB, Rijn M van de, Jeffrey SS, Rees CA, Pollack JR, Ross DT, Johnsen H, Akslen LA, Fluge O, Pergamenschikov A, Williams C, Zhu SX, Lønning PE, Børresen-Dale AL, Brown PO, Botstein D: Molecular portraits of human breast tumours. Nature 2000, 406:747-752.

5. Sørlie T, Perou CM, Tibshirani R, Aas T, Geisler S, Johnsen H, Hastie T, Eisen MB, Rijn M van de, Jeffrey SS, Thorsen T, Quist $H$, Matese JC, Brown PO, Botstein D, Eystein Lønning P, BørresenDale AL: Gene expression patterns of breast carcinomas distinguish tumor subclasses with clinical implications. Proc Natl Acad Sci USA 2001, 98:10869-10874.

6. Vijver MJ van de, He YD, van't Veer LJ, Dai H, Hart AA, Voskuil DW, Schreiber GJ, Peterse JL, Roberts C, Marton MJ, Parrish M, Atsma D, Witteveen A, Glas A, Delahaye L, Velde T van der, Bartelink H, Rodenhuis S, Rutgers ET, Friend SH, Bernards R: A geneexpression signature as a predictor of survival in breast cancer. N Engl J Med 2002, 347:1999-2009.

7. Ramaswamy S, Ross KN, Lander ES, Golub TR: A molecular signature of metastasis in primary solid tumors. Nat Genet 2003, 33:49-54

8. Weigelt B, Horlings HM, Kreike B, Hayes MM, Hauptmann M, Wessels LF, de Jong D, Vijver MJ Van de, Van't Veer LJ, Peterse
JL: Refinement of breast cancer classification by molecular characterization of histological special types. J Pathol 2008 , 216:141-150.

9. Hoch RV, Thompson DA, Baker RJ, Weigel RJ: GATA-3 is expressed in association with estrogen receptor in breast cancer. Int J Cancer 1999, 84:122-128.

10. Badve S, Turbin D, Thorat MA, Morimiya A, Nielsen TO, Perou CM, Dunn S, Huntsman DG, Nakshatri H: FOXA1 expression in breast cancer - correlation with luminal subtype $A$ and survival. Clin Cancer Res 2007, 13:4415-4421.

11. Lacroix M, Leclercq G: About GATA3, HNF3A, and XBP1, three genes co-expressed with the oestrogen receptor-alpha gene (ESR1) in breast cancer. Mol Cell Endocrinol 2004, 219:1-7.

12. Oh DS, Troester MA, Usary J, Hu Z, He X, Fan C, Wu J, Carey LA, Perou CM: Estrogen-regulated genes predict survival in hormone receptor-positive breast cancers. J Clin Oncol 2006, 24:1656-1664.

13. Carroll JS, Brown M: Estrogen receptor target gene: an evolving concept. Mol Endocrinol 2006, 20:1707-1714.

14. Carroll JS, Liu XS, Brodsky AS, Li W, Meyer CA, Szary AJ, Eeckhoute J, Shao W, Hestermann EV, Geistlinger TR, Fox EA, Silver PA, Brown M: Chromosome-wide mapping of estrogen receptor binding reveals long-range regulation requiring the forkhead protein FoxA1. Cell 2005, 122:33-43.

15. Carlsson P, Mahlapuu M: Forkhead transcription factors: key players in development and metabolism. Dev Biol 2002, 250:1-23.

16. Kaestner $\mathrm{KH}$ : The hepatocyte nuclear factor 3 (HNF3 or FOXA) family in metabolism. Trends Endocrinol Metab 2000, 11:281-285.

17. Tomaru $Y$, Kondo S, Suzuki M, Hayashizaki Y: A comprehensive search for HNF-3 $\alpha$-regulated genes in mouse hepatoma cells by $60 \mathrm{~K}$ cDNA microarray and chromatin immunoprecipitation/ PCR analysis. Biochem Biophys Res Commun 2003, 310:667-674

18. Laganiere J, Deblois G, Lefebvre C, Bataille AR, Robert F, Giguere $\mathrm{V}$ : From the cover: location analysis of estrogen receptor alpha target promoters reveals that FOXA1 defines a domain of the estrogen response. Proc Natl Acad Sci USA 2005, 102:11651-11656.

19. Liu YN, Lee WW, Wang CY, Chao TH, Chen Y, Chen JH: Regulatory mechanisms controlling human E-cadherin gene expression. Oncogene 2005, 24:8277-8290.

20. Williamson EA, Wolf I, O'Kelly J, Bose S, Tanosaki S, Koeffler HP: BRCA1 and FOXA1 proteins coregulate the expression of the cell cycle-dependent kinase inhibitor p27(Kip1). Oncogene 2006, 25:1391-1399.

21. Asselin-Labat ML, Sutherland $K D$, Barker $H$, Thomas $R$, Shackleton M, Forrest NC, Hartley L, Robb L, Grosveld FG, Wees J van der, Lindeman GJ, Visvader JE: Gata-3 is an essential regulator of mammary-gland morphogenesis and luminal-cell differentiation. Nat Cell Biol 2007, 9:201-209.

22. Kouros-Mehr H, Slorach EM, Sternlicht MD, Werb Z: GATA-3 maintains the differentiation of the luminal cell fate in the mammary gland. Cell 2006, 127:1041-1055.

23. Tong $Q$, Hotamisligil GS: Developmental biology: cell fate in the mammary gland. Nature 2007, 445:724-726.

24. Mehra R, Varambally S, Ding L, Shen R, Sabel MS, Ghosh D, Chinnaiyan AM, Kleer CG: Identification of GATA3 as a breast cancer prognostic marker by global gene expression metaanalysis. Cancer Res 2005, 65:11259-11264.

25. Bertucci F, Houlgatte R, Benziane A, Granjeaud S, Adélaïde J, Tagett R, Loriod B, Jacquemier J, Viens P, Jordan B, Birnbaum D, Nguyen $C$ : Gene expression profiling of primary breast carcinomas using arrays of candidate genes. Hum Mol Genet 2000, 9:2981-2991.

26. Gruvberger S, Ringner M, Chen $Y$, Panavally S, Saal LH, Borg A, Ferno M, Peterson C, Meltzer PS: Estrogen receptor status in breast cancer is associated with remarkably distinct gene expression patterns. Cancer Res 2001, 61:5979-5984.

27. West $M$, Blanchette $C$, Dressman $H$, Huang $E$, Ishida S, Spang $R$, Zuzan H, Olson JA Jr, Marks JR, Nevins JR: Predicting the clinical status of human breast cancer by using gene expression profiles. Proc Natl Acad Sci USA 2001, 98:11462-11467.

28. Matos I, Dufloth R, Alvarenga M, Zeferino LC, Schmitt F: p63, cytokeratin 5 , and $\mathrm{P}$-cadherin: three molecular markers to dis- 
tinguish basal phenotype in breast carcinomas. Virchows Arch 2005, 447:688-694.

29. Dufloth RM, Matos I, Schmitt F, Zeferino LC: Tissue microarrays for testing basal biomarkers in familial breast cancer cases. Sao Paulo Med J 2007, 125:226-230.

30. Paredes J, Lopes N, Milanezi F, Schmitt FC: P-cadherin and cytokeratin 5: useful adjunct markers to distinguish basal-like ductal carcinomas in situ. Virchows Arch 2007, 450:73-80.

31. Thorat MA, Marchio C, Morimiya A, Savage K, Nakshatri H, ReisFilho JS, Badve S: Forkhead box A1 expression in breast cancer is associated with luminal subtype and good prognosis. $J$ Clin Pathol 2008, 61:327-332.

32. Badve $\mathrm{S}$, Nakshatri $\mathrm{H}$ : Oestrogen receptor-positive breast cancer: towards bridging histopathologic and molecular classifications. J Clin Pathol 2009, 62:6-12.

33. Habashy HO, Powe DG, Rakha EA, Ball G, Paish C, Gee J, Nicholson RI, Ellis IO: Forkhead-box A1 (FOXA1) expression in breast cancer and its prognostic significance. Eur J Cancer 2008, 44:1541-1551.

34. Voduc $D$, Cheang $M$, Nielsen T: GATA-3 expression in breast cancer has a strong association with estrogen receptor but lacks independent prognostic value. Cancer Epidemiol Biomarkers Prev 2008, 17:365-373.

35. Perou CM, Jeffrey SS, Rijn M van de, Rees CA, Eisen MB, Ross DT, Pergamenschikov A, Williams CF, Zhu SX, Lee JC, Lashkari D, Shalon D, Brown PO, Botstein D: Distinctive gene expression patterns in human mammary epithelial cells and breast cancers. Proc Natl Acad Sci USA 1999, 96:9212-9217.

36. Doane AS, Danso M, Lal P, Donaton M, Zhang L, Hudis C, Gerald WL: An estrogen receptor-negative breast cancer subset characterized by a hormonally regulated transcriptional program and response to androgen. Oncogene 2006, 25:3994-4008.

37. Eeckhoute J, Keeton EK, Lupien M, Krum SA, Carroll JS, Brown M: Positive cross-regulatory loop ties GATA-3 to estrogen receptor alpha expression in breast cancer. Cancer Res 2007, 67:6477-6483.

38. Kouros-Mehr H, Kim JW, Bechis SK, Werb Z: GATA-3 and the regulation of the mammary luminal cell fate. Curr Opin Cell Biol 2008, 20:164-170. 